\title{
Cuerpo, naturaleza y rebelión: el componente somático en el pensamiento de Adorno y en la dialéctica negativa
}

Body, Nature and Rebellion: The Somatic component in Adorno's thought and negative dialectics

Dr. Fabrizio Fallas-Vargas

Universidad de Costa Rica (UCR) Instituto Tecnológico de Costa Rica (ITCR) fv.fabrizius@gmail.com

DOI: http://doi.org/10.15366/bp2019.21.001 Bajo Palabra. II Época. No21. Pgs: 19-38 


\section{Resumen}

En este trabajo se pretende explorar algunas de las relaciones del pensamiento de Adorno y su Dialéctica Negativa, con el "lugar" asignado al cuerpo y la naturaleza al interior del régimen de experiencia/ existencia que caracteriza la racionalidad afirmativa/ identitaria en sus más diversas manifestaciones y los distintos órdenes de lo epistémico, la ética, estética e incluso elementos libidinales. Igualmente, se pondera la necesidad de reconstruir dicho "lugar", mediante una crítica inmanente del idealismo kantiano y el racionalismo cartesiano, en orden a descifrar el "componente somático" como un campo de fuerzas soterrado y guardado bajo una secreta y paradójica combinación: el ser humano como "factor" de la naturaleza que lo excede allende su voluntad de dominio, pero también como sujeto (im)posible en el ámbito de lo político, es decir, como hybris, o desmesura.

Palabras Clave: Cuerpo, naturaleza, componente somático, Dialéctica Negativa, Adorno.

\section{Abstract}

This paper aims to explore some of the links between Adorno's thought and its $\mathrm{Ne}$ gative Dialectic, with the "place" assigned to the body and nature within the regime of experience/existence that characterizes affirmative/identity rationality in its most diverse manifestations and the different orders of the epistemic, ethics, aesthetics and even libidinal elements. Likewise, it aims to reconstruct that "place" through an immanent critique of Kantian idealism and Cartesian rationalism, in order to decipher the "somatic component" as a field of forces buried and guarded under a secret and paradoxical combination: human being as a "factor" of Nature that exceeds him beyond his will to dominate, but also as an (im) possible subject in the field of politics, that is to say, as hybris, or disproportion.

Keywords: Body, nature, somatic component, Negative Dialectics, Adorno. 
"La componente somática recuerda al conocimiento que el dolor no debe ser, que debe cambiar".

T.W. AdORNo

\section{El cuerpo como contenido bloqueado de la ratio identificatoria.}

El sujeto Cartesiano despliega la "experiencia” / "existencia” de "sí" mismo, y "su" mundo a partir de una fractura o trauma fundamental: su forma de actividad debe restringir el componente somático como fuente de conocimiento fiable e imaginarse "libre" de él: tal es la identidad primaria de la ratio objetivante que atraviesa el horizonte epistémico de la ratio afirmativa. Adorno parte de un criterio de ingreso distinto, materialista y dialéctico. En efecto, para Adorno, "el pensamiento se echa encima de la cosa, como si quisiera convertirse en acto, olor, sabor" ${ }^{1}$. El sujeto de la experiencia filosófica es para Adorno el ser humano empíricamente existente al interior de relaciones sociales materiales e históricas, es decir, un ser deseante y ante todo un cuerpo sensible, con naturaleza en su interior y exterior y cuya realización tiene lugar en el momento en el que estas relaciones sociales e históricas hacen sintagma con la negación del "sufrimiento físico", de cada individuo y de toda forma de vida $^{2}$. Es precisamente el componente somático el que recuerda al conocimiento que el desmontaje del régimen de experiencia/existencia que sirve para perpetuar el dolor debe ser transformado salvo que el sufrimiento absurdo se convierta en un valor civilizatorio.

La denuncia explícita cartesiana del componente somático del acto cognitivo, o sea, la restricción autoinflingida por el propio sujeto "activo" y "su" mundo que el experimento identitario clave de la ratio objetivante moderna comporta y que se condensa en la conclusión cogito ergo sum, conlleva el desahucio intencionado (por vía de abstracción) del componente somático de la experiencia cognitiva. Así, dentro de los contornos de este estudio, interesa proceder al análisis de esta renuncia y de las cicatrices que con ella tienen lugar al interior de la propia "racionalidad"

\footnotetext{
${ }^{1}$ Buck-Morss, Susan. Origen de la Dialéctica negativa. Theodor W. Adorno, Walter Benjamin y el Instituto de Frankfurt. México, Siglo XXI Editores, 1981, p.179.

2 Adorno, Theodor W. Dialéctica Negativa. Madrid, Taurus, 1986, p. 204.
} 
como del "sujeto" y el "objeto" (des)(con)figurados en/desde sus límites: el régimen de experiencia/existencia moderna identificatorio. En efecto, las auto restricciones del ego cogitans, y todas las precauciones de método, le guardan de establecer una articulación constructiva con el componente somático al que, desde el horizonte cartesiano, cabe denominar un "exceso" de experiencia. Es decir, que el presupuesto identitario (yoico) e identificatorio (reductor/subalternizante del objeto, incluido el cuerpo reificado) opera una relación peculiar/asimétrica del sujeto y "su" mundo que debe ser explorada dialécticamente.

Ingresar dialécticamente en esta relación implica explorar la forma en la que el sujeto paradigmático de la ratio moderna, "tramita" ese "exceso" de experiencia del

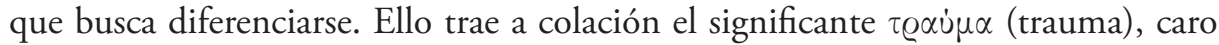
al psicoanálisis ${ }^{3}$, pero que en un sentido lato, excede los campos de la apropiación disciplinar, esto es, que el significante "trauma" remite al derivado concreto (y nada abstracto) de experiencia sobre el/los sujeto/s, bien localizadas, bien difusas, pero necesariamente somáticas, a saber: el trauma como "herida", "daño", como "desastre". La dialéctica negativa dirige sus vectores anatrépticos en orden a destruir la destrucción perpetrada por el proceso epistémico (identificatorio/clasificador/ excluyente) que sirve a la (re)producción, distribución y circulación del canon autoritario/agresivo inscrito en la regimentación de la experiencia/existencia con arreglo al patrón de poder/saber identificatorio. Ello supone restablecer los derechos de lo no-idéntico y explorar los costos asociados a la articulación destructiva con el "exceso" de experiencia que supone.

El "exceso de experiencia", en tanto que reverso de la restricción de la experiencia condensada en el ego cogitans, se manifiesta, al interior de un imaginario afirmativo cuya ratio autonomizada se proyecta hacia adentro y hacia afuera en los términos de una organización de la experiencia/existencia, sin más, esto es, sin alternativas, y cuya actuación se verifica en los términos de una renuncia "al pensamiento, que se venga en su forma reificada como matemáticas, máquina y organización, en los hombres olvidados de él" ${ }^{4}$. De ahí que es en el momento "pleno" de racionalización del patrón del poder moderno burgués, se ha alcanzado la frontera del ego cogitans, cuando queda reducido a la pasiva recepción triunfal de la propia demolición, y,

\footnotetext{
${ }^{3}$ Una primera aproximación al trámite del exceso de experiencia es remitida por Freud, a la categoría de trauma: "Llamamos así a una experiencia vivida que aporta, en poco tiempo, un aumento tan grande de excitación a la vida psíquica, que fracasa su liquidación o su elaboración por los medios normales y habituales, lo que inevitablemente da lugar a trastornos duraderos en el funcionamiento energético". Freud, Sigmund. "Conferencias de Introducción al Psicoanálisis" en Obras Completas, Vol. 15, Amorrortu, Buenos Aires, 1978, pp.200-201.

${ }^{4}$ Horkheimer, Max-Adorno, Theodor, W. Dialéctica de la Ilustración. Fragmentos filosóficos. Madrid, Trotta, 2001, pp. 93-94.
} 
al tiempo a la correspondiente sustitución por el ideal yoico condensado en las expectativas y exigencias geopolíticas y socio simbólicas de la industria cultural y la relación salarial libidinalmente investida ${ }^{5}$.

El desarrollo de la duda metódica en el programa cartesiano se detiene ahí donde advierte su momento de verdad. El espíritu de una suspicacia implacable, que llevaría a la ratio abstracta más allá de sí misma, se configura en Descartes, desde/en la experiencia del exceso, con la cual Spinoza no tuvo ningún problema al advertir la concreción que constituye el conatus cuppiditas en el terreno de la epistemología y el orden de lo político: el horizonte de la multitudo. No obstante, el filósofo francés configura un ego cuya racionalidad, en tanto que garante del conocimiento, elabora una meta extramental, esto es, la de la felicidad o contento que declara como resultado de la autoscopía y la pesquisa teorética cuyo entramado se constituye en tanto que desarticulación con la experiencia somática. En este movimiento la consciencia cartesiana logra recolocar el ideal de la traditio premoderna (agustinizante) de la renuncia al interior de los límites de la consciencia burguesa, y en ese sentido, por lo demás, kitsch, adquiere ya rango ideológico, esto es, tal ego cogitans le resulta incapaz de advertir sus propias condiciones de producción en tanto que consciencia operante y socio históricamente mediada. No obstante, y en un nivel de análisis más concreto, habría que visualizar los elementos del programa cartesiano que anuncian el exceso subyacente a la propia escritura del filósofo francés, plena de circunspección y prevenciones en torno a las posibles aplicaciones del Discurso del Método, en la medida en que se despliega en forma persistente y obsesiva a reparar la separación operada por la puesta en movimiento del método. Advirtiendo el desarrollo ulterior de sus tópicos en el ámbito de lo material, Descartes coloca en una pluralidad de lugares estratégicos, una serie de señales, o de "banderitas" para que el lector no se "pierda" en las estructuras analíticas que se sostienen sobre las ruinas de la tradición escolar, que al parecer subyacen ${ }^{6}$.

Los límites autoimpuestos del sujeto cartesiano resumen la cicatriz de la agresión (auto) dirigida contra la propia naturaleza, constante, repetida y disciplinar: tal es

\footnotetext{
5 "En lugar de la idea de la libertad respecto del trabajo aparece que uno puede elegir su trabajo. Autodeterminación significa que yo puedo deslizarme, dentro de la división del trabajo ya trazada, en el sector que me prometa la mejor tajada”. Adorno, Theodor. W. y Horkheimer, Max. Hacia un nuevo manifiesto. Buenos Aires, Eterna Cadencia, 2014, p.25.

6 “[...]mi propósito no es enseñar aquí el método que debe seguir cada uno para conducir bien su razón, sino solamente hacer ver de qué forma he tratado yo de conducir la mía. Los que se aventuran a dar preceptos se deben de juzgar más hábiles que aquellos a quienes se los dan, y si yerran en la menor cosa, son por ello censurables. Pero no proponiendo este escrito más que como una historia o, si preferís, como una fábula, en la que se encontrarán, entre algunos ejemplos que pueden ser imitados, en otros acaso que se tendrá razón para no seguir, espero que será útil a algunos sin ser dañoso a nadie, y que me quedarán todos agradecidos por mi franqueza” Descartes, René. Discurso del método. Madrid, Planeta-De Agostini, 1995, p. 5.
} 
la estructura del "goce" cartesiano en una vida teorética que le hace un idealista metafísico pero que también le distingue finalmente de un medieval en su génesis: Dios es finalmente postulado como una antropomorfización hiperbólica y bombástica, aunque el francés sostenga lo contrario insistentemente: puesto por el sujeto, procede mediante el despliegue del cogito, a conocer su naturaleza, por medio de un proceso de abstracción/subsunción que anuncia el sistema identificatorio (contra la contradicción), que tendrá fortuna posteriormente en $\mathrm{Kant}^{7}$,

El espíritu de sistema que se desarrolla tras la constatación descorporeizante del pensar incrusta la presunta necesidad de la idea de perfección, y que en Descartes funciona en forma de un vínculo ambiguo/restaurador con la traditio, pero funcional en el orden de una comunicabilidad formal ${ }^{8}$.

En razón de lo anterior, se vislumbra una forma descorporeizada de la ratio, desgarrada en sí misma a través de la forma en que busca asegurar la comunicabilidad de la duda como principio de método, introduce la función de Dios. Mediante un ejercicio analógico, Descartes intenta derivar del infinito, lo eterno y, para ello pone en juego su propia carencia o privación, ellas median la experiencia del exceso, la presencia del cuerpo que resulta abyecto: los afectos, los estados patológicos, la tristeza, están ahí, pero "me hubiera gustado estar exento de ellas". Así en la antesala de la rotura que termina de secularizar y descorporeizar la ratio con Kant, el ego cartesiano, tiene la herida aún fresca del trauma, Dios tiene aún una función: la intercomunicabilidad.

\footnotetext{
${ }^{7}$ Al respecto advierte Horkheimer en el Excursus II de la Dialéctica de la Ilustración, Juliette o Ilustración y Moral: "Para Kant, lo mismo que para Leibniz y Descartes, la racionalidad consiste en 'completar... la conexión sistemática mediante el ascenso a los géneros superiores y el descenso a las especies inferiores'. La sistematización del conocimiento es «su interconexión a partir de un solo principio». Pensar, en el sentido de la Ilustración, es producir un orden científico unitario y deducir el conocimiento de los hechos de principios, entendidos ya sea como axiomas determinados arbitrariamente, como ideas innatas o como abstracciones supremas. Las leyes lógicas constituyen las relaciones más generales dentro de ese orden; ellas lo definen. La unidad reside en la unanimidad. El principio de contradicción es el sistema in nuce. Conocer es subsumir bajo principios. El conocimiento se identifica con el juicio que integra lo particular en el sistema. Todo pensamiento que no tienda al sistema carece de dirección o es autoritario. La razón no proporciona otra cosa que la idea de unidad sistemática, los elementos formales de una sólida interconexión conceptual”. Horkheimer, Max-Adorno, Theodor W. Op.Cit. pp. 129-130.

8 “...puesto que conocía algunas perfecciones que no tenía no era yo el solo ser que existía (yo usaré aquí si lo permitís libremente, los términos de la escuela), sino que se seguía necesariamente que había algún otro ser más perfecto, del que yo dependía y del que había adquirido todo lo que tenía; pues si hubiese sido solo e independiente de cualquier otro, de modo que hubiese tenido por mí mismo todo lo poco que participaba del Ser perfecto, hubiese podido tener de mí, por la misma razón todo el exceso que sabía que me faltaba, y así, ser yo mismo infinito, eterno, inmutable, omnisciente, omnipotente $y$, en fin, tener todas las perfecciones que podía atribuir a Dios. Pues siguiendo los razonamientos que acabo de hacer, para conocer la naturaleza de Dios todo lo que la mía fuera capaz de ello, no tenía más que considerar acerca de todas las cosas, cuya idea encontraba en mí, si el poseerlas era o no perfección, y estaba seguro de que ninguna en las que notase alguna imperfección le pertenecían, pero todas las demás se daban en El; como veía que la duda, la inconstancia, la tristeza y otras cosas parecidas no podían darse en El, ya que a mí me hubiera gustado estar exento de ellas" Descartes, Op.Cit. p.29.
} 
Esto también resulta interesante, si se considera algo que en el lenguaje cientificista resulta ser un anatema, a saber: el nervio metafísico que subyace a la raída dicotomía de ciencias duras (sistemáticas) y ciencias blandas (no sistemáticas), "exactas" y "no exactas", naturales y sociales; cuyo corolario es la ubicación unilateral de la ratio abstracta -en la medida en la que responde a la forma de expresión del pensar dentro del sistema identificatorio- como si fuese la quintaesencia de la racionalidad científica (y de todo conocimiento posible), fundada en las condiciones de comunicabilidad que garantizaría un "logos" perfecto (entiéndase universal).

Tal identificación espuria del pensamiento con la ratio abstracta funda su justificación en términos meramente utilitarios/estratégicos, y en ese sentido la práctica de la $d u d a$ cartesiana enfrenta su propio exceso. Su despliegue epistemológico requiere el desahucio de la racionalidad concreta (esto sólo sería posible mediante la incorporación de los componentes somáticos y la pluralidad epistémica obturada por la diferencia identificatoria) merced a una justificación que descansa en la forma sacralizada de la ordenación de data. No es extraño, en tal sentido que el positivismo comtiano que da nacimiento a la sociología haya decantado en una religión y que en su retórica: el método positivo, la defensa del orden haga sintagma con la de una determinación del progreso que le sea funcional y que dentro del campo de lo político pueda servir a la invisibilización de sus efectualizaciones negativas. En efecto, dentro del método positivo la elaboración/valoración de la dinámica social se realiza en función de la estática, esto es, "el" progreso se encuentra bajo la égida del orden (presuntamente armónico, carente de contradicción y/o antagonismo), identitario/funcional, en la medida en que cristaliza en la reproducción continuada de un orden de asimetrías relacionales (la colonialidad), gnomológico natural/ izado y naturalizante: el ideal moderno/colonial y burgués de una sociedad bien ordenada.

La actividad del sujeto cartesiano termina ahí donde precisamente se constituyen la condiciones de su acción negativa, y es donde se encuentran en la actualidad las aspiraciones tecnocráticas inscritas dentro de la lógica cultural del capitalismo tardio, como la denomina Jameson y los esfuerzos cartesianos por dotar de investidura libidinal a la autoridad. Incluso Descartes advierte la ficción jurídica que dota de dignidad ontológica al sujeto burgués dentro de los contornos del principio de autonomía de la voluntad que subyace a las formas de las relaciones de intercambio mercantil en conformidad con la máxima de Ulpiano, pacta sunt servanda? .

9 ...me forjé una moral provisional, que no consistía más que tres o cuatro máximas que quiero participaros.

La primera era obedecer a las leyes y costumbres de mi país, manteniendo constantemente la religión en la que

Dios me ha concedido la gracia de ser educado desde mi infancia, y gobernándome en todo lo demás según 
Esta doble operación (de investidura y contento de la renuncia) configura un movimiento ulterior de la experiencia traumática en donde la violación brutal de la experiencia mimética se manifiesta en el recurso a la irracionalidad y la necesidad de mantener al sujeto bajo actividad dirigida, sin que para ello haya que considerar el autocercioramiento ni la proyección racional de fines ${ }^{10}$. El exceso que reaparece en el reverso de la duda sabotea desde dentro al ego que paradójicamente se apuntala en esta reflexión acerca sí, y Descartes, con una metáfora premoderna (aquella del bosque donde habitan los lobos y criaturas monstruosas), reproduce la instancia superyoica que aviva la lógica del trauma, la angustia producida por la pérdida de la pérdida, y, cuya astucia en este caso es el grado cero de una subjetividad aplanada en la dócil pervivencia y el goce idiota que alimenta aquello que Hegel denominaba recaída en la inmediatez y en Marx hace funcionar a la ideología. Aquello que desde una anatréptica negativa denominamos el canon de organización de la experiencia/ existencia identificatorio.

\section{La corporeización del superego moderno (identitario) o la ley mor $(t) a l$ en "mí" como universal.}

EL ANÁLISIS DE LA FRACTURA operada y actuante sobre la subjetividad moderna, (cuyo plano inmediato se encuentra ofrecido en ¿QQué es la ilustración?) convoca, dentro del campo de la crítica, identificar los desgarramientos que se inscriben al interior del proceso de sublimación de la naturaleza que se verifica en el ordo de la cultura $($ Kultur). Ello es fundamental para comprender la dialéctica kantiana de la

\footnotetext{
las opiniones más moderadas y alejadas del exceso que fuesen comúnmente recibidas en la práctica por los más sensatos entre aquellos con quienes tendría que vivir [...] estaba seguro de no poder hacer otra cosa mejor que seguir las opiniones de los más sensatos[...] entre varias opiniones igualmente recibidas, no escogía sino las más moderadas, tanto a causa de que son siempre las más cómodas de practicar, y verosímilmente (o probablemente) las mejores, siendo todo exceso habitualmente malo[...]particularmente ponía entre los excesos todas las promesas por las cuales se cercena algo de la propia libertad; no porque yo desaprobase las leyes que para remediar la inconstancia de los espíritus débiles permiten, cuando se tiene algún buen propósito, o incluso para la seguridad del comercio, si el propósito no es más que indiferente, que se hagan votos o contratos que obliguen a perseverar en ellos; pero como yo no veía en el mundo nada que siempre permaneciera en el mismo estado y, por lo que a mí respecta me comprometía a perfeccionar cada vez más mis juicios y nunca a empeorarlos[...]". Ibid. pp.19-20.

${ }^{10}$ En efecto, señala Descartes en la máxima siguiente: “[...]ser lo más firme y resuelto en mis acciones que pudiera, y no seguir menos constantemente las opiniones más dudosas, una vez que me hubiera determinado a ello, que si hubiesen sido muy seguras; imitando en esto a los viajeros que encontrándose extraviados en un bosque, no deben errar girando de un lado a otro ni menos pararse en un sitio, sino marchar siempre lo más rectamente que puedan en una misma dirección y no cambiarla por débiles razones, aunque sólo el azar acaso les haya determinado a escogerla en un principio, pues por este medio, si no llegan justamente a donde desean, al final llegarán, al menos a alguna parte, en donde verosímilmente estarán mejor que en medio de un bosque” pp. 20-21.
} 
ilustración, todavía formulada parcialmente en lenguaje metafísico, por el filósofo de Königsberg, y, de la que se desprende críticamente la noción de civilización (Zivilization ${ }^{11}$.

La elaboración crítica de esa tríada categorial -Cultura, civilización, moralidadha de partir de la forma en la que Kant teoriza acerca del papel que juega la Naturaleza (Natur) dentro de su filosofía de la historia. En efecto, lejos de representar una imagen idílica, la Naturaleza se expresa en forma sublime ${ }^{12}$, esto es, de acuerdo a la analítica kantiana, como forma caótica y sobrecogedora. En tal medida, la naturaleza conflictúa la aparente homogeneidad socio simbólica que pretende la civilización, que, no obstante, continúa su operación en la matriz sujeto/sociedad, constituyendo un pathos enteramente tenso y que funcionará como plexo articulador no idéntico, en la medida en que su carácter es parcialmente ilustrado (es decir contiene un exceso de experiencia), pero no es civilizado, y al tiempo se constituye como pre-requisito de la organización de la existencia en su regimentación material, simbólica y libidinal (cultura, en sentido amplio) ${ }^{13}$.

En razón de este vínculo, en lugar de manifestarse como extremos que no se tocan, ley moral y naturaleza hacen sintagma. Ello hace que el orden de la Moralität

${ }^{11}$ La reverberación de Rousseau en este orden de ideas, se hace manifiesta del siguiente fragmento de Kant en sus Ideas para una Historia Universal en clave cosmopolita: "[...]la naturaleza humana sufre las más penosas calamidades bajo la engańosa apariencia de un bienestar externo; de modo que Rousseau no andaba tan desencaminado al encontrar preferible ese estado de los salvajes, siempre y cuando no se tenga en cuenta esta última etapa que todavía le queda por remontar a nuestra especie. Gracias al arte y la ciencia somos extraordinariamente cultos. Estamos civilizados hasta la exageración en lo que atañe a todo tipo de cortesía social y a los buenos modales. Pero para considerarnos moralizados queda todavía mucho. Pues si bien la idea de la moralidad forma parte de la cultura, sin embargo, la aplicación de tal idea, al restringirse a las costumbres de la honestidad y de los buenos modales externos no deja de ser mera civilización". Kant, Immanuel. "Ideas para una Historia Universal en clave cosmopolita". En Ideas para una historia universal en clave cosmopolita y otros escritos sobre Filosofia de la Historia. Madrid, Tecnos, 1994, pp.16-17.

${ }^{12}$ A este respecto, resulta iluminador, el propio Kant en su obra del período precrítico: "La vista de una montaña, cuyas cimas nevadas se yerguen por encima de las nubes, la descripción de una tormenta enfurecida, o la descripción del imperio infernal que hace Milton suscitan complacencia, pero con horror. Por el contrario, el aspecto de un prado lleno de flores, valles con arroyos serpenteantes, cubiertos por rebaños pastando; la descripción del Eliseo o el relato de Homero sobre el cinturón de Venus originan también una sensación apacible, pero que es alegre y risueńa. Para que la primera impresión tenga lugar en nosotros, con intensidad apropiada, hemos de tener un sentimiento de lo sublime y, para disfrutar convenientemente la última, un sentimiento para lo bello" Kant, Immanuel. Observaciones acerca del sentimiento de lo bello y de lo sublime. Madrid, Alianza Editorial, 2012, pp. 31-32.

13 Este plexo articulador antagónico es denominado por Kant con un nombre cargado de la tensión del contradictorio y que tendrá fortuna en el psicoanálisis freudiano: la insociable sociabilidad, que constituye, de acuerdo con Kant "El medio del que se sirve la Naturaleza para llevar a cabo el desarrollo de todas sus disposiciones es el antagonismo de las mismas dentro de la sociedad, en la medida en que ese antagonismo acaba por convertirse en la causa de un orden legal de aquellas disposiciones. Entiendo aquí por antagonismo la insociable sociabilidad de los hombres, esto es, el que su inclinación a vivir en sociedad sea inseparable de una hostilidad que amenaza constantemente con disolver esa sociedad". Kant, Immanuel. Ideas para una historia universal en clave cosmopolita. Op.Cit., pp. 8-9. 
adquiera su dignidad en la autonomía y en el de la Zivilization en la Bildung (que en Kant denota el esfuerzo del sujeto por cultivar sus propias potencialidades, a través de la educación) procesos que convergen en la inestable formación de un exceso que anuda la experiencia de la Natur como sublime terrorífico, cuyo Logos permanece ignoto al tiempo que provoca una peculiar satisfacción ${ }^{14}$.

En este sentido, la Ley moral, en tanto que experiencia conflictiva hace el trabajo de la naturaleza. La ley moral, es pues, una cicatriz del esfuerzo económico, en términos psicoanalíticos, que tiene que realizar el organismo en orden a la autoconservación, en medio de una humillación constante de la que se deriva a través del cumplimiento del deber una satisfacción peculiar y perversa. Su fisonomía obedece a la estructura de una experiencia arcaica y que re-estructura el dolor experimentado por una pérdida originaria. Dicha pérdida debe ser reificada en la reproducción de la férrea ley moral en tanto que despliegue del sujeto (contra sus propias inclinaciones) que al tiempo que enuncia la universalidad de la máxima de su acción, se hace consciente de su potencia autolegisladora y de su insuficiencia constitutiva (humillación que se experimenta en los fracasos para cumplir con la severidad de la ley moral) de sujeto mortal que busca la infinitud ${ }^{15}$.

En la (ir)renunciabilidad a su pathos mortifero que se encuentra inscrito en la ley mor $(\mathrm{t})$ al que opera no en contra, sino como forma sublime de la lógica conflictiva de la Naturaleza (que en Kant tiene más bien un rostro teratológico, nada idílico ni armónico) que quiere discordia, y en este punto se alinea con su aparente antagonista: Sade, se organiza el recorrido de la violencia reproducida contra el organismo y su horizonte satisfactor, como forma de aseguramiento que evita la pérdida de la pérdida en términos de satisfacción perversa e interminable, dada sublimidad de

${ }_{14}$ De esta experiencia peculiar, de este pathos, si se quiere, da cuenta el viejo Kant en las Idee: "El hombre tiene una tendencia a socializarse, porque en tal estado siento más su condición de hombre al experimentar el desarrollo de sus disposiciones naturales, Pero también tiene una fuerte inclinación a individualizarse (aislarse), porque encuentras simultáneamente en sí mismo la insociable cualidad de doblegar todo a su mero capricho y, como se sabe propenso a oponerse a los demás, espera hallar esa misma resistencia por doquier [...] esta resistencia es aquello que despierta todas las fuerzas del hombre y le hace vencer su inclinación a la pereza, impulsándole por medio de la ambición, el afán de dominio o la codicia, a procurarse una posición entre sus congéneres, a los que no puede soportar, pero de los que tampoco es capaz de prescindir. Así se dan los primeros pasos desde la barbarie hacia la cultura [...] van desarrollándose poco a poco todos los talentos, así va formándose el gusto e incluso, mediante una continua ilustración, comienza a constituirse una manera de pensar que, andando el tiempo, puede transformar la tosca disposición natural hacia el discernimiento ético de principios prácticos determinados y, finalmente, transformar un consenso social urgido patológicamente en un ámbito moral". Idem.

15 “iDemos, pues, gracias a la Naturaleza por la incompatibilidad, por la envidiosa vanidad que nos hace rivalizar, por el anhelo insaciable de acaparar o incluso de dominar! Cosas sin las que todas las excelentes disposiciones naturales dormitarían eternamente en el seno de la humanidad sin llegar a desarrollarse jamás. El hombre quiere concordia, pero la Naturaleza sabe mejor lo que le conviene a su especie y quiere discordia”. Ibid. P. 10. 
las aspiraciones de la Moralität y su connubio con la Naturaleza. El olfato conservador del Mendelssohn, que acuña para Kant el apodo de Alles Zermalmenden, "El destroza-todo", en sus Morgenstunden de 1785, anuncia las resistencias que desde entonces el plexo de articulación al que hemos hecho alusión, suscita este pathos destrudinal ${ }^{16}$, implacable testigo arcaico y subterráneo de la autoconservación que caracteriza el despliegue de la ratio abstracta. Así, en El porvenir de una ilusión (1927/1992) advierte, en forma contundente Freud: "[...] todo individuo es virtualmente un enemigo de la cultura" ${ }^{17}$.

\section{Cuerpo, memoria y rebelión: El programa (im)posible y soterrado de la mímesis y su rango negativo.}

LA RATIO IDENTIFICATORIA HIZO DE SU ANALÍTICA un instrumento cuya "potencia" se apuntalaba en el horror por su génesis somática (aquello que no era idéntica a sí misma, ni metódica, ni sistemática). La pérdida/extrañamiento de la naturaleza interna y externa al sujeto, en la ratio identificatoria le permite organizar "su" mundo mediante la abstracción, esto es, mediante un recorte/determinación de la experiencia en el crisol del concepto. El ego identitario prepara su mundo con arreglo a sus propias categorías y lo subyuga en orden a la obtención de rendimiento epistémico ${ }^{18}$. El movimiento de abstracción deviene fin en sí mismo, y con él la relación de sujeto y objeto sin contacto o bien en líneas paralelas, esto es, sin contacto, o bien con un objeto que resulta asimilado finalmente a la expresión espiritualizada de un sujeto inflacionario (racional, autónomo y burgués) y presuntamente universal.

En Adorno se recupera el movimiento de abstracción, pero con una diferencia sensible: a sabiendas de que la abstracción es sólo un desplazamiento analítico, hay un retorno al componente somático y a la matriz natural, sin recorte, es decir, la organización de la experiencia, interpenetrada con su objeto, se satura de

\footnotetext{
${ }^{16}$ El uso del término "destrudinal" remite a su vez a la noción de "destrudo", acuñada por el psicoanalista italiano E. Weiss en 1935, para determinar el desarrollo analítico de la pulsión de muerte/destrucción iniciado por Freud en El yo y el ello (1923).

17 Freud, Sigmund. "El porvenir de una ilusión”. En Obras Completas. Buenos Aires, Amorrortu. Tomo XXI, 1992, p. 6.

${ }_{18}$ Con la categoría de rendimiento epistémico, se designa, al interior del proceso de conocimiento, por un lado: el carácter reducido de los componentes con los que el sujeto opera al objeto, (re)conociéndolo y subsumiéndole a los mismos. Por otro lado, el rendimiento deriva de la auto restricción sobrevalorada del cuerpo y la reconfiguración del mismo como un objeto pasivo de estudio, integrándole no como instancia pensante, sino como parte abyecta integrante de la naturaleza en su conjunto que se desea manipular y domeńar.
} 
concreción (que deriva del latín con-crescere, crecer con). Esta diferencia, bien es operada mediante la categoría adorniana de mímesis. La mímesis implica un exceso de experiencia (im)posible desde la ratio identificatoria, en lugar de configurar (re)conocimiento de sus propias categorías en la experiencia, incorpora aquello que no es idéntico a ellas, y en lugar de fijar la potencia en el "horror", lo hace mediante la recuperación de la dimensión somática de la experiencia/ existencia.

La potencia que se organiza desde/en la mímesis, reside, no en la pérdida, sino en la articulación constructiva. La naturaleza, en tanto que interior del sujeto, y también como matriz que le excede y de la cual es factor, ya no es un campo de operaciones y/o de distorsión ético-epistémica, contra la cual debe hacerse valer la identidad diferenciada del sujeto moderno, como sujeto activo. Lejos de convertirse en matriz de indeterminación, la recuperación del componente somático permite des-cubrirle mediante la afinidad y convoca la posibilidad negada por la ratio abstracta moderna, de destruir la diferenciación, de constituirse en/desde la afinidad y la solidaridad con todas las formas de efectualización de lo vivo. La mímesis restablece la continuidad, pero, en modo indiferenciado, y en continuidad con la naturaleza, es decir, no es un "resto de que pudiera disponer el conocimiento tras excluir los esquemas identificatorios del dispositivo categorial", sino "su negación concreta" ${ }^{19}$. El exceso de experiencia que supone no traza finitud puesto que su horizonte de temporalidad no es lineal sino más bien fractal ${ }^{20}$, y en lugar de trazar compartimentos estancos para organizar/administrar en forma antropomórfica "su" mundo, es más bien entrópica, polimorfa y disonante. La mímesis destruye la organización/administración de la experiencia y la existencia identificatorio, en sus regímenes de producción/distribución y circulación: a)Simbólico-Épistémico: $\mathrm{Al}$ romper la discontinuidad con los objetos, la mímesis permite acercarse a ellos "sin la intención de dominarlos, dejándose afectar por ellos" 21; b) Simbólico-Ético: $\mathrm{Al}$ romper con la subalternación de la naturaleza, permite al ego "conmoverse ante

19 Adorno, Theodor W. Dialéctica negativa. Madrid, Taurus, 1986, p.268.

${ }^{20}$ El término "fractal" es de origen latino y su significado remite a "roto" "quebrado" y fue acuńado en 1977 por Benoît Mandelbrot en 1977 en su libro The Fractal Geometry of Nature. El fractal posee las siguientes características: a) Dimensión no entera (número definido como irracional), b) Complejidad Estructural (independientemente de la escala de observación); c) Infinitud: A medida que el instrumento de medición es más preciso, el fractal aumenta perimetral o longitudinalmente. La idea surge de la constatación, por parte de Maldelbrot, de que "las nubes no son esferas, las montañas no son conos, las costas no son círculos, así como la corteza de un árbol no es plana ni un rayo viaja en línea recta”. Briggs, John et Al. Espejo y Reflejo. Del caos al orden. Barcelona, Gedisa,1990, p. 89. Los fractales, "constituyen un sistema descriptivo y una nueva metodología para una investigación que acaba de empezar. También pueden ser una nueva imagen de la totalidad [...] acerca de los movimientos en la totalidad”. Ibid. p. 114.

${ }_{21}$ Tafalla, Marta. Theodor W. Adorno. Una filosofía de la memoria. Barcelona, Herder, 2003, p. 132. 
el dolor de toda criatura" 22 y, procede de la mímesis "la sensibilidad hacia todos los cuerpos que sufren y hacia la naturaleza violentada" ${ }^{23}$.

La categoría adorniana de mímesis, condensa todo el malestar soterrado en la renuncia a la dimensión somática, la satisfacción del deseo, su orden quisiera buscar cancelar las premisas que llevaron a lo vivo a complejizarse a través de la lucha por la vida en la autoconservación: el deseo de retorno a lo inorgánico (destrudo), en la ausencia absoluta de estímulos. De ella procede la necesidad de romper todo núcleo de regimentación/identificación. Tal es su momento de verdad.

La mímesis no consiste salvar un horizonte vital/mortífero dominado por la naturaleza (ciega y amoral) y sus fuerzas hipertrofiadas. Desidentificarse de la renuncia que impone la ratio moderna afirmativa implica destruir la lógica de distribución que hace de la dimensión somática una forma de expresión subordinada de la experiencia y la existencia: mera res extensa o inclinación espuria; sustituir esa organización espuria y abstracta por una articulación reconciliada. Hay una promesa de bienestar (el fin de la dominación) en ella, cuyo lugar de refugio, de acuerdo con Adorno, ha sido el arte. Esta promesa expresa la no saturación de la administración de la experiencia/existencia (lo no idéntico) en/desde el disfrute, por ejemplo, de la belleza de un atardecer: la interioridad del sujeto no-enfrentado con la naturaleza.

La adaptación a largo plazo que culminó en la "unidad racional" del sujeto, mediante el imperativo de la autoconservación en la regimentación de la interioridad del sujeto y su desapego respecto de la naturaleza y sus formas de vida, "protegió" al sujeto de la indeterminación, asegurar la propia supervivencia (incluso la grupal) y le permitió organizar/unificar la experiencia/existencia en torno al régimen de lo idéntico. El relacionamiento del sujeto con la naturaleza, consigo mismo y con otros sujetos, se direcciona mediante el control y la vigilancia permanente para evitar/desplazar sus manifestaciones miméticas, y así construir "su" mundo mediante la ratio identificatoria. No obstante, esta dolorosa labor retorna sobre la organización de la existencia/experiencia en sus propios términos. Apuntalada sobre la pérdida, la pérdida de la pérdida retorna sobre esa organización experiencial, tornándole ciega y repetitiva. En una segunda naturaleza, el sujeto ofuscado ahora reprimido y autoritario, dirige su agresividad contra todo aquello que no se pliega a las medidas de esta naturaleza, y el dominio pasa a ser, ahora protegido por el encierro de la ratio: ni belleza ni verdad ni bondad serán vinculadas a lo no idéntico. No obstante, la prohibición del recuerdo de la naturaleza en el sujeto tiene implicaciones materiales: El olvido de la primera pérdida hace que la segunda sea

\footnotetext{
22 Ibid. p. 133.

23 Ibid. p. 136.
} 
irreconocible (pero no extingue el efecto somático de la renuncia ${ }^{24}$ ) y que, ahora bajo la égida de, principio identificatorio, las condiciones materiales de producción del dolor, la necesidad de control y la vigilancia productiva (dirigida al trabajo) resultan mistificadas. Así se manifiesta, sostiene Adorno la dialéctica de la razón, que, por definición es idéntica y no idéntica a la naturaleza: “[...] cuando más desenfrenadamente se convierte dentro de esta dialéctica en el adversario absoluto de la naturaleza y se olvida de ella en sí misma, tanto más retrocede hacia la naturaleza tomando los rasgos de una embrutecida autoconservación" 25 .

El materialismo del cuerpo en el que la ratio se articula conflictivamente con el deseo, reconfigura su expresión en la ética y la epistemología en la medida en que rebasa en potencia crítica al sujeto "activo" del idealismo (fijada en la abstracción intencionada del soma como fuente de mera inclinación irracional o como mera res extensa en el caso del racionalismo cartesiano). Una ética y epistemología liberada del hechizo identificatorio moderno/identificatorio ubicará en este sentido sus centros de interés, acompañando a los cuerpos sufrientes, por cuanto la persistencia del dolor es el índice de una falsa totalidad. El mundo relacional intrasubjetivo (del sujeto consigo mismo en tanto que "pedazo" de naturaleza) e intersubjetivo (con otros sujetos), lo mismo que con la naturaleza y otras especies animales se reconfigura al articular(se) con ellas, mediante la cercanía (no el distanciamiento), solidaridad (no la indiferencia) y afecto (en lugar de la agresión). El acto de conocimiento como acto violento es rebasado en una dialéctica negativa por un relacionamiento mimético y crítico: comprender que el dolor no debe ser, que la pasión y entrega al otro nacida del deseo sexual (más allá de la regimentación genitalizada y/u orientada, por un lado, a reproducción, y, por otro, al disciplinamiento produc-

${ }^{24}$ En este sentido, en Le prix du progres, Horkheimer y Adorno, utilizan una poderosa imagen para explicar la subsistencia de las huellas mnémicas del dańo somático que, sin trámite, se incorpora como cicatriz en la organización narcotizada (reificada) de la experiencia/existencia en las formaciones económico-sociales modernas: "En una carta recientemente descubierta del fisiólogo francés Pierre Flourens, a quien le tocó la triste gloria de ser elegido para la Académie Française en lugar de Victor Hugo, se encuentra un fragmento curioso: <<Aún no sé si decidirme a autorizar el empleo del cloroformo en la práctica anormal de las operaciones [...] Mis escrúpulos nacen del simple hecho de que la operación con cloroformo, como probablemente también otras formas conocidas de narcosis, representan sólo una ilusión. Tales medios obran sólo sobre ciertos centros motores y coordinadores y sobre la facultad residual de la sustancia nerviosa. Bajo la acción del cloroformo ésta pierde una parte notable de su capacidad de acoger y conservar rastros de impresiones, pero no pierde en modo alguno la sensibilidad como tal. Mis observaciones llevan de tal suerte a la conclusión de que en relación con la parálisis general de las inervaciones de los dolores son sentidos un más agudamente que en el estado normal. La ilusión del público nace de la incapacidad del paciente para recordar lo sucedido una vez que se ha ejecutado la operación. Si dijésemos la verdad a nuestros enfermos, probablemente ninguno se decidiría por tal medio, mientras que ahora, como consecuencia de nuestro silencio, insisten en que sea usado>>" Horkheimer, Max-Adorno Theodor W. Dialéctica del Iluminismo, Buenos Aires, Sur, 1969, p. 271.

25 Adorno, Theodor W. Dialéctica negativa. Madrid, Taurus, 1986, p.287. 
tivo $^{26}$ que mantiene funcionalmente concentrado y aparentemente "saludable" al individuo de cara al cumplimiento de las tareas asignadas mediante al lugar social -identitario- asignado para la (re)producción material de su existencia), hace volar en pedazos las formas de moral tutelar/desexualizada y el régimen de experiencia/ existencia epistémico moderno.

En efecto, al recuperar el cuerpo, fuente última de la única mercancía que, sin ser mercancía, produce dentro de la modernidad capitalista, todas las demás, el sujeto rompe la última cadena que lo ata al sistema de producción/ofuscación generalizada y que le condena en el abandono de sí, junto a la naturaleza, los otros animales (incluidos los humanos). El sistema no puede tolerar la emancipación del componente somático que lleva al "descentramiento del yo en el encuentro con el otro" ${ }^{27}$, en la medida en que la felicidad libre de coacción en el sexo hace de la experiencia/existencia en/con el otro una relación negativa y erótica, en la que (esto es, refractaria a la administración del deseo y al ensimismamiento del individuo competitivo) el deseo no se dirige a la afirmación del orden constituido.

El resultado al que arriba Freud en El malestar en la cultura: la felicidad no es un valor cultural $^{28}$, en la modernidad es completado por Adorno, en Intervenciones: "Lo que simplemente es idéntico a sí mismo no es capaz de felicidad" ${ }^{29}$. A ello se puede añadir que tampoco es capaz de libertad. La autonomía crítica es necesaria para una anatréptica (ética, epistemológica), como lo hizo Kant, pero no logró sacudirse de su carácter afirmativo horrorizado por las inclinaciones. Una anatréptica negativa, como en el caso adorniano recupera lo otro de la ratio sin definirla como irracional, sino como el momento concreto perdido de la misma en su momento identificatorio.

\footnotetext{
${ }^{26}$ En la Dialéctica de la Ilustración (1969), Horkheimer y Adorno recuperan la tensión Kant-Sade en la regimentación burguesa de la experiencia somática: "La afinidad entre conocimiento y plan (fundada trascendentalmente por Kant), que da a la existencia burguesa, racionalizada incluso en sus pausas, un carácter -en todos los detalles- de finalidad ineluctable, ha sido expuesta empíricamente por Sade un siglo antes del advenimiento del deporte. Las modernas escuadras deportivas, de juego colectivo perfectamente regulado, donde cada jugador sabe lo que debe hacer y hay alguien de reserva listo para sustituirlo, tienen su modelo preciso en los teams sexuales de Juliette, donde ni un instante pasa sin ser usado, no se olvida ninguna de las aberturas del cuerpo, no se deja inactiva ninguna función [...] La peculiar estructura arquitectónica del sistema kantiano, como las pirámides gímnicas de las orgías de Sade y la jerarquía de principios de las primeras logias burguesas -cuyo pendant cínico es el severo reglamento de la sociedad libertina de las 120 Journées -, preanuncia una organización de toda la vida destituida de cualquier fin objetivo. Lo que parece importar en estas instituciones, aún más que el placer, es su gestión activa y organizada [...]”. Horkheimer, Max-Adorno Theodor W. Dialéctica del Iluminismo. Op.Cit. p. 110.

27 Tafalla, Marta. Op.Cit. p. 175

${ }^{28}$ Freud, Sigmund. "El malestar en la cultura". En Obras Completas. Tomo XXI. Buenos Aíres, Amorrortu. 2003, pp. 57-140.

29 Adorno, Theodor W. Intervenciones. Nueve modelos de crítica. Caracas, Monte Ávila Editores,1969, p. 96.
} 
Es decir, que si bien el componente somático es capaz de salir de la esfera de la conciencia, no obstante es inmanente a ella y es pre-requisito de la praxis ${ }^{30}$. Una anatréptica crítica, negativa necesita de la mímesis para pensar la libertad liberada del encierro de la ética, esto es, en su fluidificación concreta en el ámbito de lo político. La tensión de la libertad (como contraste polémico con el sufrimiento que produce el canon identitario de agresión social) y la no-libertad (como imagen de ese canon) surge como una relación extramental del sujeto con el objeto. Separado del sujeto, el objeto hace ficticia la autonomía del sujeto -toda vez que de él se desprende la (im)posibilidad de la autonomía- y la crítica $^{31}$ que dan contenido a la libertad, que Adorno define como la "crítica y cambio de situaciones, no su confirmación por ellas" 32 y cuyo modelo es el disidente de Brecht (Neinsager).

La categoría de mímesis permite visualizar con Adorno, finalmente, la arquitectura de un universal concreto y que subvierte junto a la recuperación/apropiación del componente somático, el principio de intercambio (nadie en realidad importa porque al fin y al cabo cada quien deviene un bien fungible): que no hay un exterior de la vulnerabilidad al interior de la modernidad capitalista ${ }^{33}$.

A contrapelo de esta forma de definir la "dignidad de lo humano" a partir de la presunta discontinuidad con el animal, el universal concreto (no identificatorio, mimético y somático) libera al sujeto de la lógica idiotizante y cosificadora ligada al principio del canje/fungibilidad. El sujeto falso (abstracto) cuya existencia/ experiencia (interna y exterior) identificatoria se define contra-el otro, es destruido por la concreción del sujeto que ha recuperado la experiencia/existencia de sentir-pensar con-desde-en el otro, y en ese sentido, sostiene Adorno, la reciprocidad de prestaciones (propia del principio de autonomía de la voluntad de la contratación privada) es subvertida, por un ethos de lo no idéntico, en razón del cual, por un lado la "compasión" que nace de la afinidad/afectación por las "esperanzas, miedos y deseos de los demás, y congratularse con sus alegrías" 34 , y de la conciencia de que no podemos substituir al otro " ante el sufrimiento y el dolor";

\footnotetext{
30 Adorno, Theodor W. Dialéctica negativa. Op.Cit., p.228.

31 Ibid. pp. 222-223.

32 Ibíd., p. 226.

$33 \mathrm{Al}$ respecto, advierten Adorno y Horkheimer: "El hecho de que apliquen a los hombres las mismas fórmulas y resultados que ellos mismos, liberados de cadenas, obtienen en sus horrendos laboratorios fisiológicos de pobres animales indefensos, confirma la diferencia en forma particularmente malvada. La conclusión que extraen de los cuerpos mutilados de los animales no se ajusta al animal en libertad, sino al hombre actual. El hombre actual, al hacer violencia al animal, prueba que él, y sólo él en toda la creación, funciona -libremente- con la misma ciega y automática mecanicidad que los movimientos convulsivos de las víctimas encadenadas, que el técnico utiliza para sus fines”. Horkheimer, Max-Adorno Theodor W. Dialéctica del Iluminismo. Op.Cit., p. 288.

34 Tafalla, Marta. Op.Cit., pp. 187-188.
} 
y, por otro lado la generosidad del regalar, -el exceso que Nietzsche reivindicó de una moral desvinculada del abandono de la vida en sí mismo- ${ }^{35}$, dejan de ser una mera liberalidad carente de "racionalidad". Si han ese ha sido el lugar que les ha sido asignado, es porque el rasero de la ratio identificatoria y la lógica del canje no soportan su contenido material y acaso toleran su manifestación formal en la forma de wishful thinking. En la destrucción del canje, este ethos es verdadero porque no se comprende a sí mismo, esto es, va más allá de sí. El modelo de este ethos es el amor por quienes no están: los muertos. Es precisamente la comprensión de que el sufrimiento no debe ser, donde se conecta la ética, con la epistemología y sin duda a la política, porque lleva a la elucidación de las condiciones histórico- materiales de existencia, su diagnóstico y posibilidades (negadas) de transformación: el universo de la utopía ${ }^{36}$.

Mientras el tedio de la repetición, el dolor y el aburrimiento carecen de futuro, la utopía piensa/quiere el futuro, abriéndose paso por los intersticios del tiempo reificado en el olvido (la pérdida de la pérdida). Pensar la utopía, en una anatréptica negativa (y decolonial) opone una nueva tensión dialéctica: el arco de la temporalidad que es su componente mnémico. Ella consigue actualizar la consciencia de la transitoriedad de lo que es y recupera aquello que la totalidad represiva que lo reproduce ad infinitum, en la ratio moderno/colonial, envía al olvido como (im) posible y siempre postergado en forma ideológica como quimera. Al perder tensión el arco de la temporalidad, ni siquiera los muertos quedan a salvo.

Por ello desde el planteamiento adorniano el perdón no es admisible, invita al olvido y la autoincensación del presente de una cultura constituida sobre las bases de la barbarie no asumida y proyectada sobre lo que no le es idéntica. Ello reconfigura en este sentido, a la noción de justicia y de lo humano, desde lo somático y la memoria, no desde la mera reciprocidad.

Pensar lo político desde la negatividad implica, en este sentido, pensar muchos procesos de liberación, distintas temporalidades que articulan las efectualizaciones contenidas y definidas como (im)posibles, e incluso anacrónicas (más bien u-crónicas), como efecto de la solidificación mistificada de lo idéntico y sus figuras represivas (económico-políticas, simbólicas, libidinales). Mientras ello no sea así, la lógica identificatoria de la desaparición y del canje mantendrá su hechizo sin solución de

\footnotetext{
35 Ibíd., p. 187.

36 "Nunca ha habido más libertad que la voluntad que tuvieron los hombres de liberarse [...] El único modelo que hay de libertad es la intervención de la conciencia en la constitución total de la sociedad y, a través de ésta, en la estructura individual. La razón de que esto no sea una quimera radica en que la conciencia es de por sí energía impulsiva derivada, impulso también en sí misma y componente de aquello en que interviene”. Adorno, Theodor W. Dialéctica negativa. Op.Cit., pp. 263-264.
} 
continuidad: "es el pasado de las víctimas el que alberga la esperanza" ${ }^{37}$. En efecto, sostiene Adorno: "No es posible decretar de una vez por todas los escondrijos que la libertad va encontrando históricamente una y otra vez. Su concreción la adquiere en las cambiantes figuras de la represión, es decir en la resistencia contra ellas ${ }^{38}$.

El recuerdo completa el imperativo de la no admisibilidad del sufrimiento porque su universalidad es aún más concreta y negativa, y lo es, en tanto que expande las palas de su arco desde los márgenes, sin otorgar concesiones al perdón ni olvido, articulando, más allá de la historia del dominio, el recuerdo de la vida dañada: el crimen contra la humanidad y la naturaleza que a su vez integra, contra la esperanza por un tiempo nuevo. Alza su vuelo a la vista de la catástrofe, como el ángel de la historia benjaminiano.

Se trata de comprender con mucha mayor precisión, la importancia que para el pensamiento negativo posee la constelación de esperanza, negatividad y desidentificación que actualizan, podemos pensar, el campo de fuerzas en donde conocimiento (ámbito epistémico), sensibilidad (ámbito estético) y praxis (ámbito político-epistémico) articulan constructivamente lo no idéntico al interior de aquello que Adorno llama componente somático, en su relación concreta con los otros componentes: mnémico y mimético. Se trata de una episteme, de amplio espectro, definitivamente negativa y práxica, esto es, una constelación alternativa a la de muerte, historia e individuo que Adorno identifica en Dialéctica negativa con la "muerte permanente" ${ }^{39}$, una tarea pendiente pero cuya vigencia ominosa revela al tiempo la inequívoca actualidad del filósofo frankfurtiano y la urgencia de continuar con el despliegue de los vectores negativos y críticos que dinamizan su legado.

\footnotetext{
37 Ibid., p. 248.

38 Ibid., p. 263.

39 Ibid., p.370.
} 


\section{ReferenCias Bibliográficas}

Adorno, Theodor W. Dialéctica Negativa. Madrid, Taurus, 1986.

- Intervenciones. Nueve modelos de crítica. Caracas, Monte Ávila Editores,1969.

Adorno, Theodor. W. y Horkheimer, Max. Hacia un nuevo manifiesto. Buenos Aires, Eterna Cadencia, 2014.

Briggs, John et Al. Espejo y Reflejo. Del caos al orden. Barcelona, Gedisa,1990.

Buck-Morss, Susan. Origen de la Dialéctica negativa. Theodor W. Adorno, Walter Benjamin y el Instituto de Frankfurt. México, Siglo XXI Editores, 1981.

Descartes, René. Discurso del método. Madrid, Planeta-De Agostini, 1995.

Freud, Sigmund. "Conferencias de Introducción al Psicoanálisis (partes I y II)" en Obras Completas, Vol. 15, Amorrortu, Buenos Aires, 1978.

- "El malestar en la cultura". En Obras Completas. Tomo XXI. Buenos Aíres, Amorrortu. 2003, pp. 57-140.

- "El porvenir de una ilusión". En Obras Completas. Buenos Aires, Amorrortu. Tomo XXI, 1992, pp.1-55.

- El yo y el ello. En Obras completas. Tomo XIX, Buenos Aires: Amorrortu. 2006, pp.1-66.

Horkheimer, Max-Adorno Theodor W. Dialéctica del Iluminismo, Buenos Aires, Sur, 1969.

- Dialéctica de la Ilustración. Fragmentos filosóficos. Madrid, Trotta, 2001.

Kant, ImMANuel. "Ideas para una Historia Universal en clave cosmopolita". En Ideas para una historia universal en clave cosmopolita y otros escritos sobre Filosofia de la Historia. Madrid, Tecnos, 1994, pp.3-23.

- Observaciones acerca del sentimiento de lo bello y de lo sublime. Madrid, Alianza Editorial, 2012.

Tafalla, Marta. Theodor W. Adorno. Una filosofia de la memoria. Barcelona, Herder, 2003.

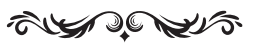

DOI: http://doi.org/10.15366/bp2019.21.001

Bajo Palabra. II Época. No21. Pgs: 19-38 
